\title{
A patient with fever, haemoptysis, and tenderness of calf muscles
}

\author{
L-W. Ding, P-H. Kuo, P-C. Yang
}

\section{Case history}

A 27-yr-old male presented to the author's emergency room on August 22, 2000, with a 5-day history of fever, chills, and tenderness of bilateral calf muscles. He also complained of diarrhoea, cough and mild haemoptysis.

The patient had a part-time job at a Chinese dessert company during summer vacations. He had been in good health previously. There was no history of blood transfusion, hepatitis, chronic liver disease, drug abuse, alcoholism or recent travel to other countries.

On examination, his consciousness was clear. Body temperature was $38.8^{\circ} \mathrm{C}$, blood pressure $130 / 90 \mathrm{mmHg}$, pulse rate 110 beats $\cdot \mathrm{min}^{-1}$, and respiratory rate 22 breaths $\cdot \mathrm{min}^{-1}$. The sclerae were icteric. The pupils were isocoric with prompt light reflex. The neck was supple, without jugular vein distension or lymphadenopathy. The chest expanded symmetrically and the breathing sounds were clear. There were no heart murmurs. The abdomen was soft and flat, without tenderness or rigidity. The liver and spleen were not palpable. The bowel sounds were active. Tenderness over bilateral calf muscles was noted. There were no skin rashes, petechiae, or ecchymosis.

Laboratory studies revealed: a white blood cell (WBC) count of $11.1 \times 10^{9}$ cells $\cdot \mathrm{L}^{-1}$, with $90.5 \%$ neutrophil, 5.3\% monocytes, and $3.5 \%$ lymphocytes; a red blood cell (RBC) count of $4.01 \times 10^{12}$ cells $\cdot \mathrm{L}^{-1}$; haemoglobin $117 \mathrm{~g} \cdot \mathrm{L}^{-1}$; and $27 \times 10^{9}$ platelets $\cdot \mathrm{L}^{-1}$. The prothrombin time and activated partial thromboplastin time were within normal limits. The asparate aminotransferase was $183 \mathrm{U} \cdot \mathrm{L}^{-1}$; the creatine kinase $3,671 \mathrm{U} \cdot \mathrm{L}^{-1}$; total bilirubin $5.8 \mathrm{mg} \cdot \mathrm{L}^{-1}$; blood urea nitrogen $150 \mathrm{mg} \cdot \mathrm{L}^{-1}$; and creatinine $14 \mathrm{mg} \cdot \mathrm{L}^{-1}$. The smears of peripheral blood were negative for parasites or microfilia. The urinalysis showed microscopic haematuria (RBC 12-15 per high power field), without RBC or WBC casts.

One day later, respiratory distress occurred and hypotension $(68 / 36 \mathrm{mmHg})$ was found on August 23, 2000. The arterial blood gases showed a $\mathrm{pH}$ of 7.41, oxygen tension in arterial blood $\left(\mathrm{Pa}_{\mathrm{a}} \mathrm{O}_{2}\right) 5.6 \mathrm{kPa}$ $(42 \mathrm{mmHg})$, carbon dioxide tension in arterial blood $\left(P \mathrm{a}, \mathrm{CO}_{2}\right) 3.7 \mathrm{kPa}(28 \mathrm{mmHg})$ and $\mathrm{HCO}_{3}{ }^{-} 17.8$ milliequivalents $(\mathrm{mEq}) \cdot \mathrm{L}^{-1}$. The patient was intubated and transferred to the intensive care unit. There was rapid progression of both hepatic and renal dysfunction. Laboratory data on August 24, 2000, revealed: total bilirubin of $153 \mathrm{mg} \cdot \mathrm{L}^{-1}$, with a direct fraction of bilirubin of $120 \mathrm{mg} \cdot \mathrm{L}^{-1}$; asparate aminotransferase $162 \mathrm{U} \cdot \mathrm{L}^{-1}$; alanine aminotransferase $57 \mathrm{U} \cdot \mathrm{L}^{-1}$; gammaglutamyl transpeptidase $86 \mathrm{U} \cdot \mathrm{L}^{-1}$; alkaline phosphatase $141 \mathrm{U} \cdot \mathrm{L}^{-1}$; blood urea nitrogen $91 \mathrm{mg} \cdot \mathrm{L}^{-1}$; and creatinine $6.7 \mathrm{mg} \cdot \mathrm{L}^{-1}$. The prothrombin time was $16 \mathrm{~s}$ (control, $12 \mathrm{~s}$ ) and the activated partial thromboplastin time was $65 \mathrm{~s}$ (control, $37.5 \mathrm{~s}$ ). The antibodies for human immunodeficiency virus and urine Legionella antigen were both negative.

On bronchoscopy, mild bleeding was found in the bronchi over both lower lungs and the bronchoalveolar lavage (BAL) fluid was bloody. The cardiac sonography showed good contractility of the left ventricle, without organic lesions or regional wall motion abnormalities. Cultures of the blood, urine and sputum, as well as the BAL fluid, failed to yield significant growth.

Imaging studies, including the initial chest radiograph on August 22, 2000 (fig. 1), the follow-up chest radiographs on the patient's third and seventh day in the hospital (figs. 2 and 3, respectively), and highresolution computed tomographs of the chest (fig. 4), are shown.

\footnotetext{
Dept of Internal Medicine, National Taiwan University Hospital, Taipei, Taiwan.

Correspondence: P-H. Kuo, Dept of Internal Medicine, National Taiwan University Hospital, No. 7, Chung-Shan South Road, Taipei 100, Taiwan. Fax: 886223582867
} 


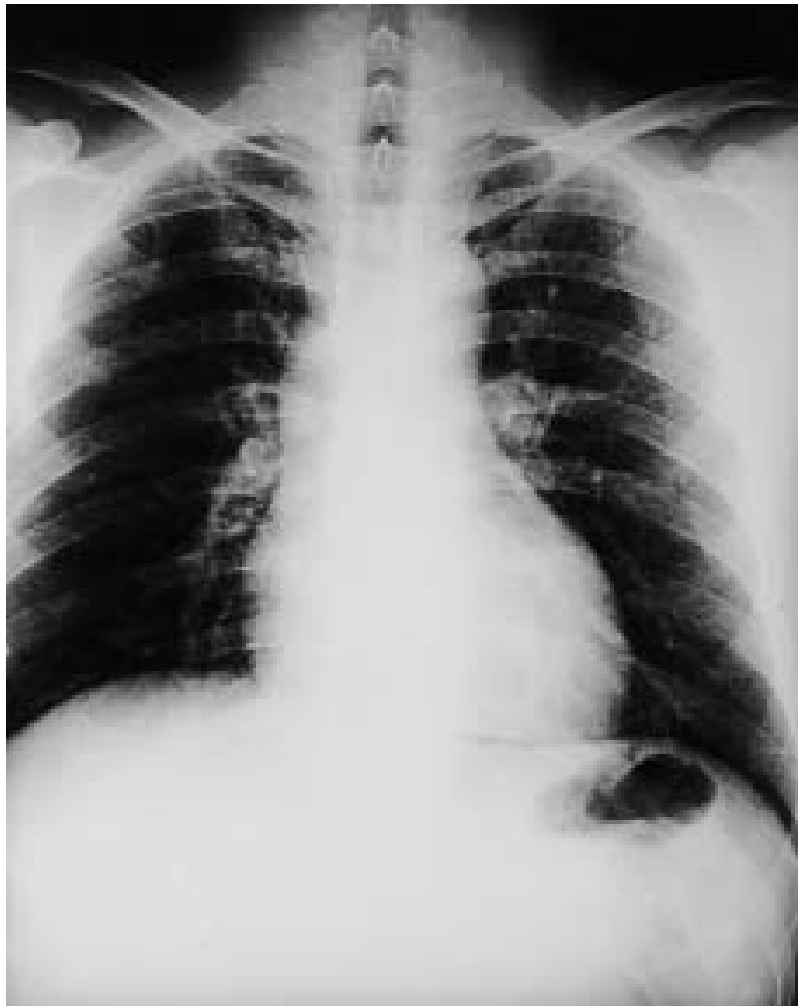

Fig. 1. - Initial chest radiograph of a 17-yr-old male after a 5-day history of fever, chills, and haemoptysis.

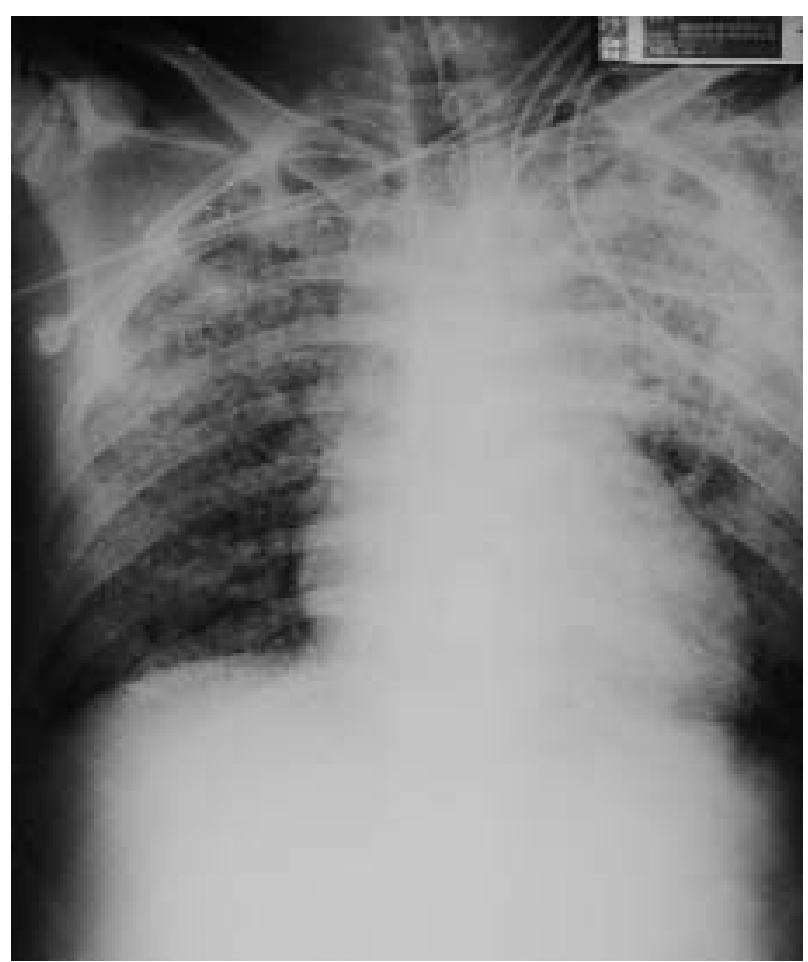

Fig. 2. - Follow-up chest radiograph 2-days later when the patient began to develop respiratory distress and hypotension.

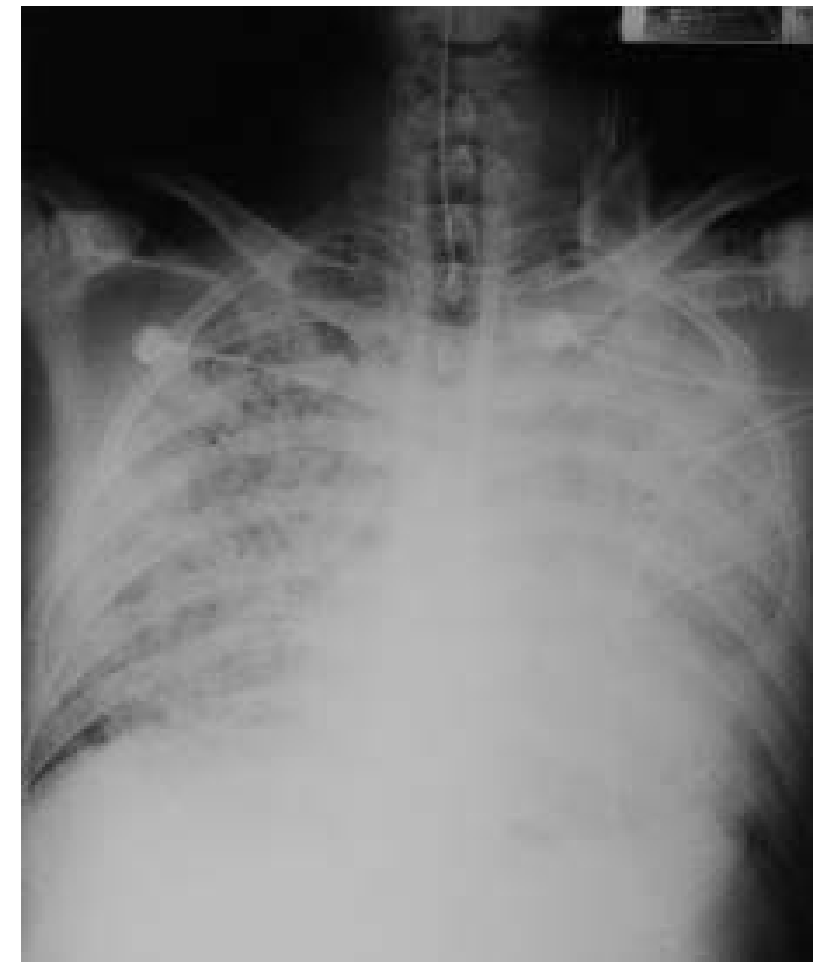

Fig. 3. - Chest radiograph taken on the 7th hospital day when the patient had profound hypoxaemia despite the use of mechanical ventilation.

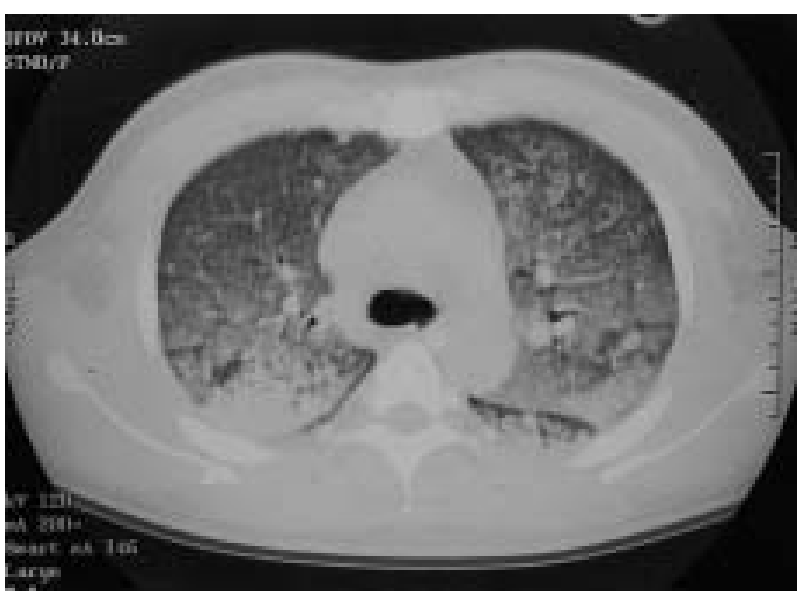

Fig. 4. - Chest computed tomography scan taken on the same day as figure 3 .

BEFORE TURNING THE PAGE, INTERPRET THE LABORATORY AND IMAGING STUDIES AND SUGGEST A DIAGNOSIS. 


\section{Interpretation of the chest radiograph and computed tomography scan}

The initial chest radiograph (fig. 1) is clear, but the follow-up images (figs. 2 and 3 ) show progression of diffuse alveolar infiltrates over bilateral lung fields. Computed tomography of the chest (fig. 4) reveals diffuse ground-glass appearance in bilateral lung fields and small patches of consolidation in bilateral lower lung fields.

Based on the clinical manifestations (fever, tenderness of calf muscles, jaundice, renal dysfunction, pulmonary haemorrhage, and respiratory failure), the diagnosis of Weil's syndrome was highly suspected. Leptospirosis was confirmed based on an initial microagglutination antibody titre of $1: 200$ and an eight-fold rise $(1: 1,600)$ in the paired serum 7 days later.

Diagnosis: "Severe leptospirosis with hepatorenal dysfunction, pulmonary haemorrhage and acute respiratory distress syndrome"

\section{Course and treatment}

Penicillin G, 12 million $\mathrm{U} \cdot \mathrm{day}^{-1}$, was administered but was shifted to minocycline, $400 \mathrm{mg} \cdot \mathrm{day}^{-1}$, on August 29, 2000 due to drug allergy. Pressurecontrolled ventilation with intermittent prone positioning was required to maintain oxygen saturation at $\geqslant 90 \%$. The chest radiograph and multi-organ dysfunction improved gradually and the patient was finally liberated from mechanical ventilation on September 6, 2000. Minocycline therapy was maintained for 2 weeks and the patient was discharged on the 20th day of hospitalization. When he was last seen at the outpatient clinic on October 2, 2000, he was rather well and the chest radiograph and all laboratory data were normal.

\section{Discussion}

Leptospirosis is an uncommon zoonosis and usually presents with multisystem involvement. The symptoms of leptospirosis include fever, muscle tenderness (especially of the calf muscles), headache, conjunctival suffusion, and digestive disorders with mild hepatic and renal involvement. Weil's syndrome, characterized by hepatorenal dysfunction, mental status change, and haemorrhagic diathesis, may also appear. Furthermore, leptospirosis is also associated with cardiovascular collapse and significant mortality. Diseases that should be listed in the differential diagnosis of Weil's syndrome include richettsiosis, malaria, typhoid fever, Kawasaki disease, yellow fever, septicaemia, toxic shock syndrome, Hantaan virus infection and Legionnaires' disease [1].

Pulmonary manifestations in leptospirosis are not uncommon, but symptoms are usually mild and often overshadowed by other organ involvement. Patients with acute respiratory distress syndrome (ARDS) who require mechanical ventilation, as in the case presented here, are rare. There are two forms of pulmonary involvement in leptospirosis: the benign type, in which the patient recovers without sequlae, and the severe type that may be fatal $[2,3]$. A nonproductive cough is the most common pulmonary symptom, occurring in $20-70 \%$ of cases, and is prominent at the beginning of the leptospiremic phase. Haemoptysis has been reported in $3-25 \%$ of patients and chest pain may occur in 10\% [4]. Abnormal chest radiographs are found in $5-10 \%$ of cases with respiratory symptoms, and infiltrates are presented in $82 \%$ of patients with haemoptysis. Radiological manifestations of leptospirosis are seen most frequently between the third and ninth day of the disease. The common chest radiographic appearance is of a scattered alveolar haemorrhage with patchy alveolar infiltrates, which have a similar appearance to snowflakes, which occurs in $45-60 \%$ of the patients. Radiological manifestations are most common in the lower lobes and the peripheral lung fields, which correspond to areas of maximum blood flow and capillary density $[5,6]$.

ARDS and alveolar haemorrhage are two of the most fatal conditions in leptospirosis. This association has been recognized in the last 20 yrs. However, the aetiology of ARDS cannot be explained entirely and the neutrophil-mediated mechanism seems less probable, given the lack of inflammation noted in pathological studies. Thus, the possibility of a JarischHerxheimer reaction has to be considered [7].

The pathophysiology of pulmonary injury in leptospirosis is poorly understood. Vascular injury and haemorrhagic diathesis are prominent features of the illness, but the mechanism of endothelial lesions is not clear. Two principal hypotheses are presented here. The first indicates a direct action of the spirochaete on the membrane of parenchymal cells. This action may initially cause functional disorders of these membranes, only later leading to necrosis. Vascular damage may be due to the same process that occurs in endothelial cells. In contrast, the second hypothesis is related to undefined leptospiral toxin causing endothelial damage to pulmonary capillaries [8]. In the lungs, the damage to capillary endothelia is manifested predominantly as haemorrhagic pneumonitis. Lung specimens obtained at post mortem show diffuse petechiae and focal haemorrhagic lesions, most commonly in the lower lobes [9].

The diagnosis of leptospirosis is based on epidemiological history, clinical manifestations, and laboratory findings. The most common way of confirming a diagnosis of leptospirosis is by serology. Macroagglutination is a simple method, but the microscopic agglutination test is more specific. In positive cases, seroconversion is observed with at least a four-fold rise in microagglutination titre.

The majority of cases need no specific treatment because the disease usually resolves spontaneously. The prompt correction of dehydration, hypovolaemia, hypotension, and electrolyte imbalance is important. Most authorities agree that if antibiotics are not started before the 4th day, they do not change the course of the illness [10]. The most effective drug regimen is penicillin $\mathrm{G}, 100,000 \mathrm{U} \cdot \mathrm{kg}^{-1} \cdot 24 \mathrm{~h}^{-1}$ (in divided doses every 3-4 h), or tetracycline, $25-40 \mathrm{mg} \cdot \mathrm{kg}^{-1} \cdot \mathrm{day}^{-1}$ (in divided doses every $6 \mathrm{~h}$ ), given over 7 days. 
As leptospiral infection is endemic throughout the world, including large urban areas, physicians should consider leptospiral infection in the differential diagnosis of acute alveolar haemorrhage and in the diagnosis of acute respiratory failure. Leptospiral infection should also be considered in acute respiratory distress syndrome patients who have an appropriate epidemiological history.

\section{References}

1. Michael KH, Charles VS. Leptospiral pneumonia. Semin Respir Infect 1997; 12: 4449.

2. Eduardo PB, Carlos RRC. Pulmonary leptospirosis. Curr Opin Pulm Med 2000; 6: 436-441.

3. Bethlem N, Lemle A, Pereira NG. Leptospirosis. Sem Respir Med 1991; 12: 58-67.

4. O'Neil KM, Rickman LS, Lazarus AA. Pulmonary manifestations of leptospirosis. Rev Infect Dis 1991; 13: 705-709.
5. Burke BJ, Searle JF, Mattingly D. Leptospirosis presenting with profuse haemoptysis. BMJ 1976; 2: 982.

6. Im JG, Yeon KM, Han MC, et al. Leptospirosis of the lung: radiographic findings in 58 patients. Am $J$ Roentgenol 1989; 152: 955-959.

7. Emmanouilides CE, Kohn OF, Garibaldi R. Leptospirosis complicated by a Jarisch-Herxheimer reaction and adult respiratory distress syndrome: case report. Clin Infect Dis 1994; 18: 1004-1006.

8. Nicodemo AC, Duarte MIS, Alves VAF, Takakura CF, Santos RT, Nicodemo EL. Lung lesions in human leptospirosis: Microscopic, immunohistochemical, and ultrastructural features related to thrombocytopenia. Am J Trop Med Hyg 1997; 56: 181-187.

9. Edwards G, Domm BM. Human leptospirosis. Medicine 1960; 39: 117-156.

10. Watt G, Padre LP, Tuazon ML. Placebo-controlled trial of intravenous penicillin for severe and late leptospirosis. Lancet 1988; 1: 433-435. 